\title{
A ÉTICA FILOSÓFICA DO UBUNTU NA SALA DE AULA: UM DEBATE SOBRE 0 RACISMO NO FUTEBOL BRASILEIRO
}

\author{
Carlos Eduardo Gomes Nascimento ${ }^{1}$
}

Da Liberdade eram mito,

No rosto a dor do aflito,

Negra a cor da escravidão(...)

Da nossa vida primeira,

Foram a luz verdadeira

Das nossas crenças perdidas

Luiz Gama

RESUMO: O artigo apresenta a prática docente no Programa Institucional de Bolsa de Iniciação à Docência (PIBID), no curso de licenciatura em Filosofia, sobre o tema: a ética do ubuntu, um princípio da filosofia africana. O texto é resultado da pesquisa e realização da atividade com os estudantes do ensino médio no Colégio Estadual Duque de Caxias em Salvador na Bahia, objetivando o diálogo filosófico em sala de aula, através da reflexão crítica e social acerca da existência dos casos de injúria racial no Brasil, em especial, no futebol brasileiro. O texto, também, evidencia a importância do PIBID na construção de projetos na educação básica, que possibilitam a ressignificação do olhar do sujeito enquanto 
futuro docente de filosofia no ensino médio. Com efeito, a relação entre filosofia e educação, segundo a vivência da filosofia africana da ética do ubuntu, pode possibilitar uma experiência filosófica e didática na luta contra o racismo.

PALAVRAS-CHAVE: Filosofia Africana; Educação; Racismo e Ubuntu.

ABSTRACT: The article presents the teaching practice in the Programa Institucional de Bolsa de Iniciação à Docência (PIBID) in the course Philosophy at Universidade Federal da Bahia on the theme: the ethics of ubuntu, a principle of African philosophy. The text is the result of research and realization of activity with high school students in the Colégio Estadual Duque de Caxias in Salvador de Bahia, aiming the philosophical dialogue in the classroom, through criticism and social reflection about the existence of cases of racial slur in Brazil, especially in Brazilian football. The text also highlights the importance of PIBID in construction projects in basic education, which make it possible to reframe the subject's view as future teachers of philosophy in high school. Indeed, the relationship between philosophy and education, according to the experience of African philosophy of ubuntu ethic, can allow a philosophical and didactic experience in the fight against racism.

KEYWORDS: African Philosophy; Education; Racism and Ubuntu. 


\section{INTRODUÇÃO}

O país do futebol é racista? A aparente ideia de democracia racial existente no Brasil parece ser uma idealização criada na imagem do futebol como esporte popular e democrático, que une ricos e pobres, brancos, negros, índios e mestiços, principalmente, por conta da visibilidade mundial do talento dos jogadores brasileiros, que em sua maioria são descentes de homens negros e que, na história do Brasil, foram subjugados à condição de escravizados, até o dia 13 de maio do ano de 1888, quando foi sancionada, pela princesa Isabel, a Lei Imperial no 3.353, chamada "Lei Áurea", que declarava extinta a escravidão no Brasil.

Por outro lado, no decorrer do século, se iniciou um novo processo de segregação social no Brasil que atingiu homens, mulheres, crianças, jovens e velhos, em sua maioria negros, em um processo de marginalização política e econômica, conforme as lições de Darcy Ribeiro em seu livro $O$ povo brasileiro - a formação e o sentido do Brasil (1995):

Em consequência, os ex-escravos abandonam as fazendas em que labutavam, ganham as estradas à procura de terrenos baldios em que pudessem acampar, para viverem livres como se estivessem nos quilombos, plantando milho e mandioca para comer. Caíram, então, em tal condição de miserabilidade que a população negra reduziu-se substancialmente (RIBEIRO, 1995, p. 228).

Nesta perspectiva, a ação do projeto "A ética filosófica do ubuntu na sala de aula: um debate sobre o racismo no futebol brasileiro" do Programa de Iniciação à Docência 
e Coordenação de Aperfeiçoamento de Pessoal de Nível Superior (PIBID/CAPES), no curso de licenciatura de filosofia da Universidade Federal da Bahia (UFBA), pretende a mobilização da comunidade escolar, abarcando, principalmente, os estudantes do ensino médio, os professores, gestores educacionais e responsáveis, na imanência de uma reflexão da consciência humana sobre a formação étnica da cultura negra para o Colégio Duque de Caxias, que está localizado no bairro periférico e histórico da Liberdade, onde ocorreram várias batalhas pela Independência da Bahia, em 1823.

O bairro da Liberdade faz parte da região da periferia de Salvador, que apesar de ser berço de diversos movimentos por ações afirmativas e políticas públicas de reparação para os brasileiros de matriz africana, ainda carece de infraestruturas básicas e medidas de assistências nas áreas de saúde e educação, para a sua população constituída do maior número de moradores negros na cidade.

Com a finalidade de provocar nos alunos do Colégio Duque de Caxias uma reflexão ética dos valores universais da relação entre os homens, mulheres e o mundo, por meio da mudança do olhar filosófico europeu para a prática filosófica e espiritual, através da vivência ética do $u b u n t u$, um princípio fundamental e essencial da filosofia africana, a fim de fomentar o debate acerca da problemática do estudo de caso - o racismo, que de maneira geral está interligado à condição social e política que se encontra a construção histórica do sujeito.

Trazer uma reflexão sobre as formas de combate contra o racismo, que ainda está entranhado na vida cotidiana da 
sociedade brasileira, visto que os estudantes do Colégio Duque de Caxias são em sua maioria afrodescendentes, permite que possam construir um olhar singular, a partir de uma perspectiva de resistência contra a subjugação do sujeito aos discursos de poder, como é o caso do racismo. Com isso, a atividade identifica os diversos modos que o discurso de racismo, por parte da sociedade brasileira, vem aparecendo em vários meios de comunicação, evidenciando a sua existência no Brasil, não apenas nas relações sociais, como também no futebol brasileiro.

Deste modo, a temática do projeto explora o conceito filosófico africano, na prática ética do ubuntu, contra a violência do regime racista e segregacionista do apartheid, ocorrido durante todo o século XX, na África do Sul, suprimindo pela violência física os direitos e princípios da dignidade humana dos homens e mulheres negros em favor de uma pequena elite branca, enquanto o resto do mundo ficava de braços cruzados, indiferente às mazelas vividas pelo povo negro sul-africano.

A partir daí a ideia do projeto a ser desenvolvido em sala de aula para estudantes do ensino médio tem como guia o resgate do espírito do conceito ético do ubuntu praticado por Nelson Mandela, que se elegeu presidente da África do Sul em 1994, e Desmond Tutu, conhecido líder espiritual sulafricano na resistência contra o feroz racismo praticado pelas instituições e na busca de reconciliação entre os homens na África do Sul.

No Brasil, atualmente, é através da paixão nacional pelo futebol que a ideia de uma convivência pacífica e do respeito às diferenças vem caindo por terra, diante dos 
recentes casos de crime de injúria racial, que demonstra uma realidade assustadora nos campos de futebol do país, onde se acreditou que poderia haver o princípio de igualdade que está indissociável da efetivação democrática, isto é, asseverando a ideia do sociólogo Florestan Fernandes no livro: A integração do negro na sociedade de classes, de que no Brasil se vive uma ideia do "mito da democracia racial"2, posto que, após abolição, os negros nunca foram tratados como iguais.

Assim sendo, o projeto é composto de dois momentos: No primeiro momento, articulação junto aos estudantes com a exposição deste conceito da filosofia africana sobre o significado histórico e humano da prática ética do ubuntu. Por conseguinte, no segundo momento, faz-se a formação estrutural para o recurso estratégico a ser desenvolvido na sala, propondo no plano de aula, a realização do debate que deve envolver todos os estudantes da turma de ensino médio, sob a orientação do professor supervisor, mas com a participação de todo o coletivo de bolsistas do PIBID de filosofia do Colégio Duque de Caxias, acerca das problemáticas centrais, que devem ser exploradas pela turma: Existe o racismo no Brasil e no futebol brasileiro? Por que o racismo se contrapõe aos princípios éticos? Através da ideia do conceito ético do ubuntu é possível mudar esta realidade no Brasil?

Cada estudante elabora individualmente um texto dissertativo-argumentativo, com a finalidade de exposição do ponto de vista de cada um sobre o tema proposto, no caso, o combate ao racismo, em que devem ser observadas, de modo fundamentado os elementos desenvolvidos durante as etapas anteriores. Espera-se que os alunos escrevam sobre a mudança do olhar do sujeito ético, tomando por princípio ético, em 
filosofia africana, a prática do conceito do $u b u n t u$, diante dos casos de injuria racial no futebol brasileiro, resguardando que é um dever de todos os cidadãos em denunciar este crime para as instituições legais competentes.

\section{A AÇÃO PARA O PROJETO: ENSINOE APRENDIZAGEM DO CONCEITO FILOSÓFICO}

No processo de ensino de filosofia, cabe ao professor observar se o estudante aprendeu a lidar com o conceito filosófico e se ele será capaz de conseguir organizar e expor sua opinião fundamentada nas leituras colhidas no decorrer do processo, isto é, se a aprendizagem sobre o conteúdo filosófico de fato está expressa nos argumentos desenvolvidos pelo estudante.

Este processo é para que o jovem possa escrever um texto crítico, a partir de um contexto filosófico, expressando-se por meio de argumentos que põem em análise o senso comum, a fim de se tornar um sujeito consciente e aberto ao conhecimento em sua liberdade de pensar e se expressar coletivamente.

A atividade objetiva superar a dificuldade de construção de gêneros textuais dissertativos, a partir de temas filosóficos, tendo como foco o tema "A prática ética do ubuntu como forma de resistência e combate ao racismo no Brasil", para que se possa trazer para o estudante um espírito de reflexão sobre a formação histórica da organização social e política no Brasil.

Com isso, o projeto tem como um potencial impacto a provocação da necessidade e da importância de se aprender Filosofia no ensino médio, isto é, o despertar para o exercício 
filosófico, saindo do senso comum e indo em direção a uma consciência crítica, que é exigida tanto na formação educacional por um cidadão ativo e que possa ser um agente crítico transformador da sua realidade.

Os recursos estratégicos para a ação do projeto consistem na leitura de trechos de textos críticos de natureza filosófica, sociológica, jornalística e também jurídica, que serão a base para comunicação oral, através de um debate mediado pelos bolsistas, que vivenciam a experiência da licenciatura em filosofia. A atividade é supervisionada pelo professor, fomentando a interpretação dos textos, verbais e imagéticos, no desenvolvimento do espírito crítico e argumentativo dos estudantes.

A aplicação do projeto deve estar em conformidade com o conteúdo programático organizado pelo professor supervisor do Colégio Estadual Duque de Caxias, visto que o projeto em desenvolvimento envolve uma ação coletiva entre todos bolsistas do PIBID de Filosofia e a comunidade do colégio, na dinâmica transdisciplinar entre o conteúdo de filosofia que também poder abarcar os objetivos com outras disciplinas, como artes, literatura, história e sociologia, com a finalidade de compartilhar o conhecimento e contribuir para o ensino e aprendizagem em filosofia na comunidade escolar.

O planejamento escolar deve fazer parte deste processo de humanização na reflexão e análise que atravessa todo um campo de acesso ao conhecimento da construção histórica da realidade social brasileira. Com isso, a análise do contexto da prática social e educativa não se deve limitar à área das ciências pedagógicas, apenas, mas para todos os conteúdos 
explorados no ensino médio, de maneira transdisciplinar. Sendo assim, as ideias então desenvolvidas atravessam como um fio condutor para uma ressignificação da educação no Brasil.

As novas dimensões e o impacto das questões em exposição para os estudantes de ensino médio sobre o tema do racismo no futebol surgem para que o planejamento didático na escola que possa formular novas diretrizes, tanto no seu campo teórico e metodológico quanto prático no uso de suas atribuições e competências frente às diversas situações cotidianamente encontradas na realidade brasileira.

\section{A ÉTICA FILOSÓFICA DO UBUNTU NA SALA DE AULA}

O ubuntu é o espírito ou princípio filosófico fundamental da vida do povo africano, sendo um conceito que compõe o reconhecimento do ser humano consigo mesmo e com os outros, por uma indelével experiência entre os homens, mulheres e o mundo em uma harmonia universal.

A construção conceitual dos princípios da ética ocidental, que estão na origem das cidades-estados, pólis, na Grécia Clássica ( $\mathrm{V}$ a. C.), tive como fonte marcante o aparecimento do pensamento filosófico, em especial, a filosofia de Sócrates, que é considerado o pai da filosofia ética no ocidente. Nesta esteira, podemos encontrar caraterísticas em comum com o espírito do ubuntu, o que pode ser observado na expressão filosófica do cuidado de si e cuidado dos outros, quando Sócrates chama atenção dos cidadãos de Atenas: 
Tu ateniense, cidadão da maior cidade e mais célebre por sabedoria e poder, não te envergonhes de pensar em acumular o máximo de riquezas, fama e honras, sem te preocupar em cuidar da inteligência, da verdade e da tua alma, para que se tornem tão boas quanto possível? (PLATÃO, 2000, p. 88).

Deste mesmo modo, a filosofia grega em sua origem possuía na sua prática ética uma preocupação com o princípio universal do cuidado com a alma (psykhé), a saber, a alma como um princípio de natureza ou espiritual, vital para a convivência entre os homens, que deve ser continuamente cuidado, a fim de cultivar a paz e o diálogo na formação política da comunidade humana.

$\mathrm{O}$ pesquisador moçambicano José $\mathrm{P}$. Castiano, no livro Referenciais da Filosofia Africana (2010), traz uma leitura da expressão de vida e da prática ética do ubuntu com as concepções conceituais da filosofia ocidental:

Ubu-ntu é a categoria epistemológica e ontológica fundamental no pensamento dos povos Bantu, expressando o ubu uma compreensão generalizada da realidade ontológica do Ser enquanto Ser, e o ntu assumindo formas e modos concretos de existência num processo contínuo (CASTIANO, 2010, p.156).

O princípio filosófico e ético do ubuntu ganha um caráter de modo de vida para os sujeitos que buscam a liberdade como uma condição ontológica indissociável da prática dos valores humanos éticos. Este espírito livre e de resistência foi descrito no manifesto do movimento da juventude do The African 
National Congress (ANC), Congresso Nacional Africano (CNA), que contou com a participação de Nelson Mandela, em 1944. Neste manifesto está descrito em um dos seus princípios, o pensamento ético do ubuntu: "O africano quer o universo como um todo orgânico que tende à harmonia e no qual as partes individuais existem somente como aspectos da unidade universal".

A prática ética do ubuntu representou a experiência da tradição filosófica do homem negro contra a violência na reconciliação política e na constituição de sujeitos. Agruras e sofrimento do povo negro não significou o esquecimento, mas um fator de resistência por uma luta na ressignificação dos sujeitos. Por esta razão, o princípio da prática ética do ubuntu, como revela Mandela em entrevista quando diz: "eu só posso ser eu através de você e com você", pode parecer-nos estranho, mas poderá sinalizar para um caminho de criação de uma ideia ou princípio que poderá unir a sociedade brasileira plural.

Neste contexto, mesmo com a existência de uma cultura de mercado para o consumo, que prega o sujeito individualista, tornando o sujeito uma coisa a ser explorada, gerando uma "confusão dos espíritos" (2015, p.50), conforme diz Milton Santos no livro Por uma outra globalização do pensamento único à consciência universal. Esta confusão sobre ser dos sujeitos acaba sendo a tônica dominante produzida pelo poder mídia sobre a opinião pública na realidade social brasileira, onde o político é cooptado pelo poder econômico, assim como em muitos países em desenvolvimento. Com isso, a busca por um pensamento de uma "consciência universal" na prática ética da filosofia africana do ubuntu 
na construção da realidade social do Brasil pode vir a ser uma perspectiva de ressignificação para o sujeito que não conhece sua história.

Isto é, para que o brasileiro, em especial o afrodescendente, possa encontrar novos caminhos para compreender sua própria história, visto que muitos homens, mulheres e crianças do grupo etnolinguístico "Banto" (ba-ntu, significa "humanos") da África Subsaariana foram trazidos e escravizados aqui no Brasil e mesmo assim resistiram e reproduziram sua visão de mundo dentro da formação histórica e sociocultural brasileira, o projeto aqui explorado visa em certa medida resgatar o pensamento presente na nossa formação cultural brasileira.

Com efeito, a prática do racismo, testemunhada em atos ocorridos no Brasil, em especial nos recentes casos no futebol brasileiro, configura o crime de injúria racial, que está previsto no Art. 140. $\S 3^{\circ}$ do Código Penal Brasileiro: "Injuriar alguém, ofendendo-lhe a dignidade ou o decoro na utilização de elementos referentes a raça, cor, etnia, religião, origem ou a condição de pessoa idosa ou portadora de deficiência. Pena de reclusão de um a três anos e multa".

Porém, o que devemos combater e trazer ao espírito de reflexão filosófica dos jovens estudantes é que aqueles que cometem esse tipo de crime, que ofende o princípio da dignidade da pessoa humana, através do preconceito e da discriminação, seja por raça, gênero, sexo, condição social ou psicofísica, acabam tendo uma condenação ética diante de si mesmo e jurídica perante toda a sociedade, que não pode aceitar mais este tipo de ato hediondo. 


\section{POR UMA RESSIGNIFICAÇÃO DO OLHAR DO DOCENTE DE FILOSOFIA}

O pensamento africano por um longo tempo foi negligenciado e marginalizado nas salas de aula do Brasil resultado de uma tentativa de apagar o seu passado escravocrata, uma vez que mesmo nos dias atuais a questão do abismo socioeconômico entre brancos e negros não foi dirimida. Basta reconhecer o alto índice de desemprego e morte dos jovens negros no Brasil, evidenciando um retrato trágico da forma que o sistema de repressão do Estado age pelo braço armado das suas polícias.

Por outro lado, a Lei ${ }^{\circ} 10.639 / 2003$, que estabeleceu a inclusão da temática da história e cultura afro-brasileira no ensino básico, ainda é fonte de estranheza em boa parte da sociedade brasileira. A Lei regulamentou um outro olhar do sujeito para os estudantes e professores no ensino básico, que necessitam refletir a história das ideias no Brasil, através do entendimento genealógico da nossa constituição histórica enquanto sujeitos.

Com efeito, os africanos e seus descendentes não tinham voz nem vez, pois eram o objeto da história dos outros, dos fenômenos históricos no período da modernidade de repressão ao sujeito: o colonialismo dos séculos XVI ao XVIII e neocolonialismo do século XIX e XX, conforme descreve Michel Foucault em seu curso no Collège de France, que foi transformado em livro Em Defesa da Sociedade (2009): 
Nunca se deve esquecer que a colonização, com suas técnicas e suas armas políticas e jurídicas, transportou, claro, modelos europeus para outros continentes (...) Houve toda uma série de modelos coloniais que foram trazidos para o Ocidente e que fez com que o Ocidente pudesse praticar também em si mesmo algo como uma colonização, um colonialismo interno (FOUCAULT, 2010, p. 86).

O regime segregacionista e racista do apartheid na África do Sul, teve o respaldo da prática discursiva da modernidade do sistema colonialista, trazido pela pretensa lógica universal da ciência, na produção de discursos de poder sobre a subjetividade, a fim de fundamentar a inferioridade dos colonizados e escravizados, tal como divulgou a razão do pensamento iluminista de Voltaire sobre africanos escravizados pelo domínio europeu, em suas Cartas filosóficas (2008), que foram enviadas para o cientista natural Linnaeu,

A raça negra é uma espécie humana tão diferente da nossa quanto a raça de cachorros spaniel e dos galgos, pode se dizer que a sua compreensão, mesmo que não seja de natureza diferente da nossa, é pelo menos muito inferior (VOLTAIRE, 2008, p. 54).

Deste modo, a razão dos colonizadores infligiu ao continente africano não apenas na exploração dos recursos naturais (pelas potências econômicas europeias e norteamericana), mas também no sacrífico da carne e na subjugação da alma do povo escravizado, segundo a cor da pele, nos quatros cantos do mundo, onde teve sua cultura e manifestações 
religiosas negadas e suprimidas, principalmente, por fontes normativas das instituições do Estado.

Como, por exemplo, ocorreu no Brasil, após a abolição da escravatura, a criminalização da prática da capoeira, pelo Código Penal, de 1890, que prescrevia: "Art. 402. Fazer nas ruas e praças públicas exercício de agilidade e destreza corporal conhecida pela denominação capoeiragem. Pena de prisão por dois a seis meses". Demonstrando a tentativa de dominar o corpo e o espírito dos afrodescendentes, para assim qualificá-los como vadios e torná-los homens dóceis para o Estado ${ }^{3}$.

Se deve então questionar: será mesmo que a reflexão da prática dos princípios éticos na modernidade, por meio da relação entre a ideia de sujeito e a busca da autonomia e da liberdade contra a sujeição histórico cultural, só pode ser articulada para os jovens do Ensino Médio nos colégios públicos no Brasil, unicamente através da realização do pensamento filosófico europeu?

O debate nas aulas de filosofia, geralmente guiados pelos livros didáticos, contempla, por vezes, somente como as únicas perspectivas de se pensar e agir nesta relação ética entre o sujeito e a liberdade segundo o pensamento europeu. No entanto, em particular, os professores de filosofia, que estão na linha de frente da educação brasileira, em propor aos seus alunos outras experiências para a construção de um sujeito ético, que não deve apenas se contentar com a exposição das experiências vindas do continente europeu, mas também com outro olhar sobre a constituição do sujeito.

Com efeito, trazer outro olhar para o sujeito por meio do pensamento africano poderá ampliar as perspectivas 
sobre a ética, a partir de diferentes maneiras de lidar com o conhecimento e com a maneira como o sujeito em liberdade vem a se relacionar com todo o mundo humano e natural. Nesta esteira, ressalta no artigo "Filosofia da ancestralidade como filosofia africana: educação e cultura afro-brasileira", o professor e educador Eduardo David de Oliveira:

Os temas da Ética, da Política e da Epistemologia são privilegiados e abordados de acordo com uma perspectiva geopolítica e geocultural que resultarão, em síntese, na perspectiva da Ancestralidade. Em solo brasileiro, a Filosofia da Ancestralidade reivindica para seu fazer filosófico a tradição dinâmica dos povos africanos - especialmente a tríade: nagô, jêje e banto-, como leitmotiv do filosofar (OLIVEIRA, 2012, p. 30).

É o momento do educador brasileiro e professor de filosofia, que carrega também em seus genes o DNA oriundo do continente africano abrir os olhos para a sua convivência no cotidiano com a cultura de matriz africana, para assim emergir novos referenciais de subjetividade, a fim de despertar os indivíduos na relação ensino-aprendizagem, por um método no pensamento do professor Dante Gallefi: "filosofar transdisciplinar que não é regido pela mecânica do conhecimento sedimentado e instituído, pois se guia pelo indeterminado e pela abertura radical para a atividade de investigação permanente" (GALLEFI,2013, p.5).

Contudo, os professores e educadores devem estar sempre atentos às novas experiências na educação, por uma tomada autônoma de consciência e ação livre para os 
sujeitos em formação cultural, isto é, a partir da atitude e da transformação do pensamento em uma sociedade tão diversa como é a brasileira, almejando outro horizonte, mais plural, para as formas de pensar o amor ao saber, a filosofia, nas relações humanas.

\section{CONSIDERAÇÕES FINAIS}

Os bolsistas do PIBID serão em sua maioria os futuros profissionais da educação nas escolas da rede pública de ensino. Enquanto, futuros educadores devem desde já ter a capacidade de identificar a problemática e explorar soluções e experiências do cotidiano para que a ação de ensinar e aprender tenha uma grande força na tarefa humana e histórica na nova construção da realidade social brasileira e na afirmação do anseio por liberdade, por justiça e de luta para todos os cidadãos brasileiros.

O critério de ação ética, que vincula professores e estudantes junto ao mundo, carece de maior ampliação de ideias nas salas de aula do Brasil para que assim possa ser estimulado um diálogo fecundo e criativo com outras matrizes de pensamento. Deste modo, trazer para sala de aula o princípio ético do ubuntu, como uma experiência do pensamento e da vida humana que está imanente na filosofia africana pode vir a se tornar uma fonte de encantamento para o processo do ensino e aprendizagem entre o licenciando em filosofia e os jovens estudantes brasileiros.

Com efeito, a construção da liberdade intelectual e cultural para os educadores no Brasil deve passar por um 
esforço de transformação dos referenciais de subjetivação para que agora o brasileiro, dono da descoberta de sua própria história, possa se revelar enquanto sujeito transformador do processo educacional no Brasil. Portanto, a lição do princípio ético do ubuntu no presente projeto para o PIBID de Filosofia no Colégio Duque de Caxias quer alcançar a esperança aos jovens estudantes na construção de uma nova experiência filosófica para a sociedade brasileira sem qualquer discriminação.

\section{NOTAS}

'É estudante do curso de licenciatura em Filosofia da Universidade Federal da Bahia. E-mail: carlos_gomes02@hotmail.com;

${ }^{2}$ Acerca da ideia de democracia racial no Brasil podemos ler no prefácio de Gilberto Freyre no livro "Negro no futebol brasileiro" (1947) de Mario Filho, assim diz Freyre: "O futebol, no brasil, ao engrandecer-se em instituição nacional, engrandecesse também o negro, o descendente de negro, o mulato, o cafuzo, o mestiço. E entre os meios mais recentes - isto é, dos últimos vinte ou trinta anos - de ascensão social do negro no Brasil, nenhum excede em importância, ao do futebol" (FILHO, 2003, p. 24).

${ }^{3} \mathrm{Com}$ isso, podemos lembrar a luta contra discursos racistas na ciência da criminologia, aqui na Bahia, principalmente por Nina Rodrigues que buscava provar por evidências empíricas a predisposição do negro ao crime. Manuel Querino, intelectual baiano, assume a responsabilidade e resistência contra aquele racismo científico, em diversos textos como $O$ colono preto como fator da civilização brasileira (1918): "Foi o trabalho do negro que aqui sustentou por séculos e sem desfalecimento, a nobreza e a prosperidade do Brasil: foi com o produto de seu trabalho que tivemos as instituições científicas, letras, artes, comércio, indústria, etc., competindo-lhe, portanto, um lugar de destaque que, como fator da civilização brasileira" (QUERINO, 2013). 


\section{REFERÊNCIAS}

CASTIANO, José P. Referenciais da Filosofia Africana Em busca da Inter subjetivação. Moçambique: Publicada pela Universidade de Desenvolvimento da Educação Básica na Província de Gaza. 2010. Link: https://pt.scribd. $\mathrm{com} / \mathrm{doc} / 108807202 / J o s e-P-C a s t i a n o-R e f e r e n c i a i s-d a-$ Filosofia-Africana-Em-busca-da-intersubjectivacao_ Acesso em 13 de setembro de 2014.

FERNANDES, F. A Integração do Negro na Sociedade de Classes. $3^{a}$ ed. São Paulo: Ática, 1978.

FILHO, Mario. O Negro no futebol brasileiro. São Paulo: Mauad, 2003.

FOUCAUlT, M. Em Defesa da Sociedade. São Paulo: Ed. Martins Fontes, 2009.

GALEFFI, D. Por que ensinar Filosofia hoje? Texto apresentado em: II Simpósio Estadual sobre o Ensino de Filosofia da UERN: Mossoró, 2013.

GAMA, Luiz. Primeiras trovas burlescas de Getúlio. Salvador: Editora P55, 2011.

OLIVEIRA, E. D. Filosofia da ancestralidade como filosofia africana: educação e cultura afro-brasileira. Revista SulAmericana de Filosofia e Educação. Número 18: maioout/2012, p. 28-47. Link: http://periodicos.unb.br/index. $\mathrm{php} / \mathrm{resafe} /$ article/view/7029. Acesso em 13 de setembro de 2014. 
PLATÃO. Apologia In. Coleção Pensadores. São Paulo: Editora Nova Cultural, 2000.

QUERINO, M. O colono preto como fator da civilização brasileira. Salvador. Editora P55, 2013.

RIBEIRO, D. O Povo Brasileiro - A Formação e o Sentido do Brasil. São Paulo: Editora Companhia das Letras, 1995.

SANTOS, M. Por uma outra globalização do pensamento único à consciência universal. São Paulo: Editora Record, 2015.

VOLTAIRE. Cartas Filosóficas. Tradução Marcia Valeria Martinez de Aguiar. São Paulo: Editora Martins Fontes, 2008.

Vídeo: Nelson Mandela Link: https://www.youtube.com/ watch? $=9 \mathrm{QnEaKZ} \_4 \mathrm{kY}$. 